\title{
OPEM
}

www.opem.org

Oriental Pharmacy and Experimental Medicine 2009 9(3), 245-251

DOI 10.3742/OPEM.2009.9.3.245

\section{Aldose reductase inhibitory activity and anti catraract potential of some traditionally acclaimed antidiabetic medicinal plants}

\author{
Mayurkumar B Patel* and Shrihari M Mishra \\ Pharmacy Department, Kalabhavan, Faculty of Technology and Engineering, The M S University of Baroda Vadodara - \\ 390 001, Gujarat, India
}

Received for publication August 11, 2008; accepted March 13, 2009

\begin{abstract}
SUMMARY
Aldose reductase (AR) has been reported to play an important role in sugar-induced cataract. In the present study, the AR inhibitory activity of Enicostemma hyssopifolium (EH), Gymnema sylvestre, Eclipta alba, and Tinospora cordifolia (TC) were studied along with their effect on sugar-induced cataractogenic changes in sheep lenses in vitro. AR inhibitory activity of the aqueous extracts of plants and their anticataract potentials were evaluated in vitro in sheep lenses, considering the activity of normal sheep lenses as $100 \%$. The concentration of the plant extract that showed maximum activity was selected to further study its effect on galactose-induced polyol accumulation in vitro. The $\mathrm{IC}_{50}$ values of $\mathrm{EH}$ and TC were calculated to be 102 and $85 \mu \mathrm{g} / \mathrm{ml}$, respectively. EH showed a significant inhibition (61.3\%) in polyol accumulation followed by TC (53.1\%). EH and TC possesses a significant anticataract activity in vitro and its anticataract potential could be related with its AR inhibitory effect.
\end{abstract}

Key words: Aldose reductase; Cataract; Eclipta alba; Enicostemma hyssopifolium; Gymnema sylvestre; Polyol; Tinospora cordifolia

\section{INTRODUCTION}

Increased blood sugar levels influence the refractive power of the lens in diabetics, and can lead to diabetic cataract. Surplus glucose induces accumulation of the sugar alcohol within the cells, thus generating disturbances of the osmotic balance and finally causing cataract. The enzyme aldose reductase is the first enzyme of the polyol pathway (Fig. 1) that reduces excess D-glucose into D-sorbitol with concomitant conversion of

*Correspondence: Mayurkumar B Patel, Pharmacy Department, Kalabhavan, Faculty of Technology and Engineering, The M S University of Baroda Vadodara 390 001, Gujarat, India. Tel: +91 0265 2434187; Fax: +91 0265 2423898; E-mail: mayur.pharma@gmail.com
NADPH into NADP ${ }^{+}$(Kador, 1988; Carper et al., 1989; Tomlinson et al., 1994; Crabbe and Goode, 1998; Yabe-Nishimura, 1998).

Experiments with animals have shown that aldose reductase inhibitors can prevent the formation of such opacities in streptozotocininduced diabetic rats (Kim et al., 2008). Aldose reductase is the key enzyme of polyol pathway and has been a drug target in the clinical treatment of secondary complications of diabetes including cataract (Tomlinson et al., 1994). Literature review showed that the cataract progression can be slowed or prevented by the use of natural therapies, particularly with those plants having high flavonoids content and have shown considerable in vivo AR inhibiting effect (Lim et al., 2001) and hypoglycemic 


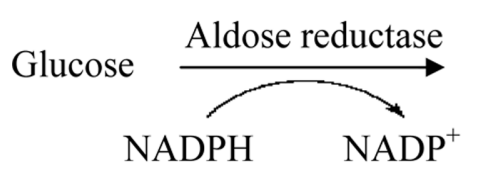

Fig. 1. Polyol pathway.

activity. Some aldose reductase inhibitors from natural sources like vitamin C, ellagic acid, dehydrocorydaline, maesanin, flaviolin, salvianolic acid, perillosides A-D etc. are known and studied well (Fuente and Manzanaro, 2003). In the search of newer aldose reductase inhibitors from natural source, the present study was undertaken to explore the aldose reductase inhibitory activity of 4 well reported hypoglycemic plants. In the present study, aqueous extracts of four reputed antidiabetic plants viz. Enicostemma hyssopifolium (Vijayvargia et al., 2000; Vasu et al., 2002; Srinivasan et al., 2005), Gymnema sylvestre (Baskaran et al., 1990; Shanmugasundaram et al., 1990), Eclipta alba (Ananthi et al., 2003), and Tinospora cordifolia (Wadood et al., 1992; Stanely et al., 2000) were selected to evaluate their AR inhibiting potential and anticataract activity in vitro. The selection criteria of aqueous extracts of plants relied on their reported hypoglycemic activity and their usage as common ingredient of many antidiabetic polyherbal formulations.

\section{MATERIALS AND METHODS}

\section{Plant extracts}

The fresh plants were collected from the village nearby Junagadh district, Gujarat, India, and were authenticated as Enicostemma hyssopifolium Verdoon (Gentianaceae), Tinospora cordifolia (Willd.) Miers ex Hook .F. and Thoms (Menispermaceae), Gymnema sylvestre (Retz.) R.Br. ex Schult (Asclepediaceae), and Eclipta alba (L.) Hassk. (Compositae) at Botanical Survey of India, Pune. Voucher specimen has been deposited in herbarium of our laboratory for future reference and numbers are given as EH1/Samp1, TC1/samp3, GS1/Samp4, and EA1/ Samp2 respectively. Aerial parts of all the plants were dried under shade and powdered. Aqueous

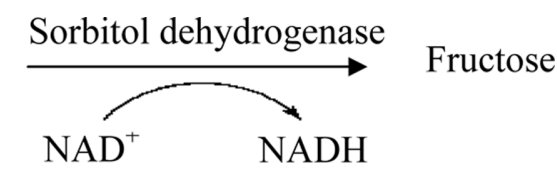

extracts were prepared by cold maceration for $24 \mathrm{~h}$. They were filtered and filtrates were dried under vacuum at $50^{\circ} \mathrm{C}$ using rota-evaporator. Dried extracts were kept in dessicator overnight and then were stored at low temperature $\left(2-8^{\circ} \mathrm{C}\right)$ in refrigerator. Extracts were reconstituted in phosphate buffer saline (PBS) for subsequent experimental studies.

\section{Chemicals}

D-xylose, sodium carbonate, galactose, galactitol, quercetin, Dulbecco's modified eagle's medium (DMEM), fetal calf serum, adenine dinucleotide phosphate reduced form (NADPH) were purchase from Himedia, India. All other chemicals like, ammonium sulfate, dimethyl sulfoxide, lithium sulfate, perchloric acid, potassium hydroxide, periodic acid, stannous chloride and chromotropic acid were of analytical grade and procured from Qualigens, India.

\section{Enzyme preparation from lens homogenate}

Sheep eyes were obtained from a local abattoir soon after slaughtering, and the lenses were enucleated by making lateral incision and frozen until needed. The supernatant fraction of the sheep lens homogenate was prepared according to the procedures of Hayman and Kinoshita (Hayman and Kinoshita, 1965). Briefly Lenses (10 - 12 g) were homogenized in 3 volumes of cold distilled water in a teflon paddled homogenizer and centrifuged at $10,000 \times g$ for $15 \mathrm{~min}$ to remove insoluble material. Saturated ammonium sulfate was added to the supernatant fluid to $40 \%$ saturation. The thick suspension had been allowed to stand with occasional stirring for $15 \mathrm{~min}$ to ensure complete precipitation. It was centrifuged and the precipitate was discarded. Additional inert protein was removed by 
increasing the ammonium sulfate concentration to $50 \%$ saturation and centrifuging the mixture. Aldose reductase was then precipitated from the $50 \%$ supernatant solution by the addition of saturated ammonium sulfate solution up to $75 \%$ saturation and was recovered by centrifugation. The pellet obtained by centrifugation was dissolved in the phosphate buffer $(0.067 \mathrm{M})$. Further purification of the fraction was done with the use of Sephadex LH 20 (Sigma-Aldrich, USA). Enzyme preparation was analyzed for its protein content using Lowry's method (Lowry et al., 1951).

\section{Sample preparation}

Dried extracts were reconstituted in 5\% DMSO in phosphate buffer to prepare stock solutions. Various dilutions of final concentration 25, 50, 75, 100, 200, 300 and $400 \mu \mathrm{g} / \mathrm{ml}$ were prepared.

\section{Determination of AR activity}

Lens AR activity was measured according to the method of Hayman and Kinoshita with slight modification. In short, the reaction mixture was prepared at $25^{\circ} \mathrm{C}$, with a total volume of $3.0 \mathrm{ml}$, containing $50 \mathrm{mM}$ Na-phosphate buffer ( $\mathrm{pH}$ 6.2), $0.125 \mathrm{mM}$ NADPH, $400 \mathrm{mM} \mathrm{LiSO} 4,0.3 \mathrm{ml}$ of enzyme preparation and $10 \mathrm{mM}$ D-xylose as a substrate with or without plant extract. The reaction was initiated by addition of NADPH and continued for $5 \mathrm{~min}$. Absorbance was recorded in a double beam spectrophotometer at $340 \mathrm{~nm}$, at every $30 \mathrm{~s}$ intervals for $5 \mathrm{~min}$. A negative control was prepared using $5 \%$ DMSO in phosphate buffer (pH 6.2). The bioassays were run in triplicate and the average inhibitory activities of the extracts were calculated using the following formula.

$\%$ AR Inhibition $=$

$\Delta$ Abs. (Negative Control) - $\Delta$ Abs. (Extract) $\Delta$ Abs. (Negative Control)

To determine the AR inhibiting activity, $0.3 \mathrm{ml}$ of plant extract from various stock solutions was added to both the reference and sample cuvettes. The reaction was initiated by the addition of $0.3 \mathrm{ml}$ of $0.125 \mathrm{mM}$ NADPH in sample cuvette and the rate of reaction was measured as described above. $\Delta \mathrm{OD} / \mathrm{min} / \mathrm{mg}$ protein was calculated for each sample. Percent inhibition of AR activity was calculated and $\mathrm{IC}_{50}$ value for each extract was obtained from a dose-response curve.

\section{Effect on polyol level under osmotic stress}

Eyes were enucleated and lenses were dissected from the sheep eyes. Each isolated lens was incubated in $5 \mathrm{ml}$ of DMEM at $37^{\circ} \mathrm{C}$ in an incubator at $95 \%$ air and $5 \% \mathrm{CO}_{2}$ (Halder et al., 2003). The medium was supplemented with $10 \%$ fetal calf serum and $0.9 \mathrm{~g} / 1$ sodium bicarbonate. Streptomycin, $100 \mu \mathrm{g} / \mathrm{ml}$ and penicillin, $100 \mathrm{IU} / \mathrm{ml}$ were also added to prevent bacterial contamination. After $2 \mathrm{~h}$ of incubation, opaque lenses which were damaged during dissection were discarded and transparent lenses were taken for the subsequent experimental studies. Osmotic stress was generated by supplementing galactose (GAL; $30 \mathrm{mM}$ ) in the DMEM culture medium. To standardize the incubation period in presence of GAL, enucleated clear lenses were incubated for different time periods such as 1, 3, and $5 \mathrm{~h}$ at $37^{\circ} \mathrm{C}$ with $5 \% \mathrm{CO}_{2}$ and $95 \%$ air. The time period of maximum polyol accumulation was calculated to be $3 \mathrm{~h}$, which was considered for the subsequent experiments. The transparent sheep lenses were divided into negative control, positive control and treated groups. Negative control, positive control and treated group's lenses were incubated for $3 \mathrm{~h}$ in DMEM, DMEM supplemented with $30 \mathrm{mM}$ of GAL and quercetin $(33.3 \mathrm{mM})$, and DMEM supplemented with $30 \mathrm{mM}$ of GAL as well as the concentration of the extract with maximum AR inhibitory activity shown in the previous experiment, respectively. Post-incubation, lenses from different groups were washed, fresh weight recorded and processed for polyol estimation by the reported method (West and Rapoport, 1949). Briefly, the lenses were homogenized in 9 volumes 
of $0.6 \mathrm{~N}$ perchloric acid and centrifuged at $5,000 \times g$ for $20 \mathrm{~min}$. The supernatant so obtained was neutralized with $2 \mathrm{~N} \mathrm{KOH}$ and again centrifuged. The supernatant was reacted with $0.25 \mathrm{ml}$ of periodic acid $(0.03 \mathrm{M})$ for $10 \mathrm{~min}$ followed by the addition of freshly prepared $0.25 \mathrm{ml}$ of stannous chloride $(0.125 \mathrm{M})$ and $2.5 \mathrm{ml}$ of chromotropic acid $(0.2 \%)$. The reaction mixture was heated on a boiling water bath for $30 \mathrm{~min}$. The absorbance of the purple-colored complex was measured at 570 $\mathrm{nm}$ using spectrophotometer. A parallel standard was also prepared using galactitol.

\section{RESULTS}

The phytochemical screening of aqueous extracts revealed that EH contains significant amount of flavonoids, coumarins, bitter principles and carbohydrates, EA found to have phenolics, mainly coumestans as well as carbohydrates and proteins, TC contains terpene glycosides, alkaloids, flavonoids and carbohydrates, GS found to be rich in saponin content and also shows presence of carbohydrates and proteins.

\section{Inhibition of lens AR}

The effects of the aqueous extract were estimated with the aldose reductase enzyme, using D-xylose as a substrate. Their inhibitory potencies and $\mathrm{IC}_{50}$ values on the AR enzyme were estimated. The average inhibitory activities of the extracts were

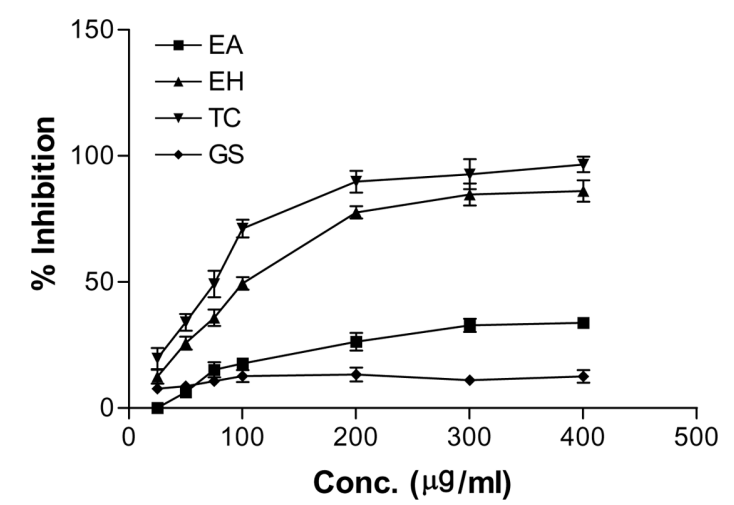

Fig. 2. The effect of TC, EH, EA and GS on AR activity in sheep lenses. Each value is mean \pm S.E.M. of three observations.

calculated and shown in Table 1. Aqueous extracts of TC and EH were found to inhibit lens AR. It is evident from the dose response curve that TC offered maximum AR inhibiting activity followed by EH. Inhibitory activity of EA and GS was not significant when compared with negative control. At the concentration of $200 \mu \mathrm{g} / \mathrm{ml}$, TC showed AR inhibition by $89.8 \%$. The AR inhibitory activity of $\mathrm{TC}, \mathrm{EH}, \mathrm{EA}$, and GS at different concentrations is presented in Fig. 2. It is evident from the DRC that the maximum inhibitory effect of TC and EH was produced at the concentration of $200 \mu \mathrm{g} / \mathrm{ml}$ for both, and $\mathrm{IC}_{50}$ value was calculated to be 85 and $102 \mu \mathrm{g} / \mathrm{ml}$ respectively.

\section{Effects on lens polyol}

Polyol content in sheep lenses maintained in organ

Table 1. AR Inhibitory activity of extracts

\begin{tabular}{crrrr}
\hline $\begin{array}{c}\text { Concentration } \\
(\mu \mathrm{g} / \mathrm{ml})\end{array}$ & \multicolumn{4}{c}{ \% Inhibition } \\
\cline { 2 - 5 } & \multicolumn{1}{c}{ EA } & EH & \multicolumn{1}{c}{ TC } & \multicolumn{1}{c}{ GS } \\
\hline 25 & $0.00 \pm 0.00$ & $12.45 \pm 1.57$ & $19.66 \pm 2.42$ & $7.70 \pm 0.32$ \\
50 & $6.29 \pm 0.73$ & $25.75 \pm 1.47$ & $34.00 \pm 1.91$ & $8.70 \pm 0.71$ \\
75 & $15.16 \pm 1.74$ & $35.82 \pm 1.90$ & $49.15 \pm 3.02$ & $10.70 \pm 0.83$ \\
100 & $17.75 \pm 0.72$ & $49.43 \pm 1.43$ & $71.20 \pm 2.04$ & $12.70 \pm 1.37$ \\
200 & $26.31 \pm 2.03$ & $77.62 \pm 1.42$ & $89.80 \pm 2.49$ & $13.27 \pm 1.59$ \\
300 & $32.82 \pm 1.48$ & $84.67 \pm 2.55$ & $92.72 \pm 3.44$ & $11.05 \pm 0.94$ \\
400 & $33.82 \pm 1.18$ & $86.03 \pm 2.45$ & $96.58 \pm 1.77$ & $12.60 \pm 1.44$ \\
\hline
\end{tabular}

Each value is mean \pm S.E.M. of three observations. 


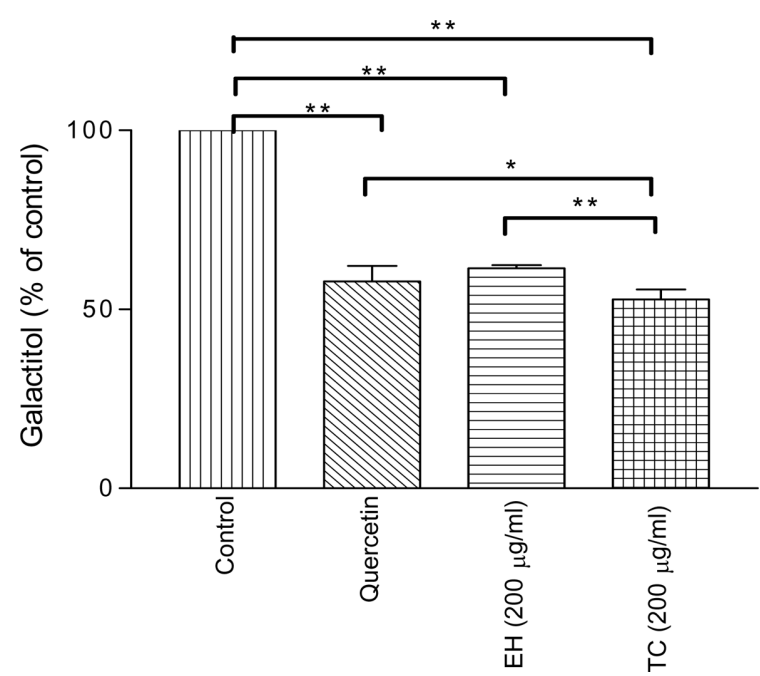

Fig. 3. The effect of EH and TC on polyol accumulation in lenses cultured in a GAL- medium. ${ }^{*} P<0.05,{ }^{* *} P<$ 0.001. ( $n=5$, data analyzed by one-way ANOVA followed by Bonferroni's Multiple Comparision Test).

culture under high galactosemic condition is presented in Fig. 3. The effect of herbal extracts on polyol levels was studied at $3 \mathrm{~h}$, the time of maximum polyol accumulation. The most effective AR inhibitory concentration of TC and EH i.e. $200 \mu \mathrm{g} / \mathrm{ml}$ was used to see their effect on polyol accumulation. EH present in a GAL medium significantly decreased the lens polyol to $61.3 \%$ in comparison to control group whereas the polyol level in TC treated lenses was found to be 53.1 in comparison to the control lenses. EA and GS were excluded from this experiment.

\section{Statistical analysis}

Data of polyol content in lenses were analyzed by one-way ANOVA followed by Bonferroni's Multiple Comparision Test. $P$ values less than 0.05 were considered as significant.

\section{DISCUSSION}

Significant production of polyol in the lens during sugar-induced cataractogenesis stimulated intense interest in the pathological role of polyol pathway in the development of cataract. Polyol accumulation in the lens leads to an increase in the intracellular ionic strength resulting in excessive hydration, eventually loss of membrane integrity and leakage of free amino acids, glutathione and myo-inositol (Heyningen,1959) etc. Aldose reductase is found to be the primary factor responsible for this pathological condition (Heyningen, 1959). Human genetic and biochemical data also suggested a strong link between raised AR activity and strongly altered risk of diabetic complications such as cataract, nephropathy, retinopathy and neuropathy (Collier and Small, 1991). These results together with recent clinical, experimental and pharmacological data provide powerful support for research and development of AR Inhibitors. There are many reports of AR inhibiting activity of natural products such as Eugenia borinquensis, Mangifera indica, Eucalyptus deglupta, and Syzygium malaccense (Guzman and Guerrero, 2005). Ellagic acid and two of its derivatives were found as a potent aldose reductase inhibitors in the leaves of Myrciaria dubia (Ueda et al., 2004). Three flavonoids isolated from Brickellia arguta showed anticataract activity in rats (Rosler et al., 1984). Acteoside, an active aldose reductase inhibitor phenolic glycoside was discovered from a $70 \%$ acetone extract of Monochasma savatierii (Kohda et al., 1989). Monoterpene glycosides, perillosides A and $C$ isolated from the leaves of Perilla frutescens were found to be excellent aldose reductase inhibitor (Kohda et al., 1995). Some sulfated flavonoids in Polygonum hydropiper were discovered to show potent inhibition against bovine lens aldose reductase (Haraguchi et al., 1996). Other studies showed that flavonoid glycosides (Haraguchi et al., 1998), isoflavonoids (Jung et al., 2002), flavanone glucosides (myrciacitrins III) (Suryanarayana et al., 2004), protocatechualdehyde (Suryanarayana et al., 2002) and tannoid principles (Lee et al., 2005) had strong inhibitory activity. Plants which are rich in polyphenols and bioflavonoids are reported to reduce the AR activity. Diabetes being the major risk factor for cataract, the plants for the present study has been 
selected on the basis of their reported hypoglycemic property. Selected plant's aqueous extracts were studied for their AR inhibiting activity and, subsequently, their anticataract potential was evaluated against GAL-induced biochemical changes in sheep lenses maintained in organ culture in the presence and absence of the extracts. The results of the present study suggest that TC and EH possess AR inhibiting activity of different magnitude. Most of the reported natural AR inhibitors are phenolic compounds and in addition to inhibition of the polyol pathway, they are also involved in anti oxidant mechanisms, like the flavonoids and vitamin $\mathrm{C}$, in the inhibition of the overproduction of superoxide (Brownlee, 2001) or in metal ion chelation processes (Crabbe and Goode, 1998). The aqueous extract of $T$. cordifolia has shown the antioxidant action in diabetic rats (Prince and Menon, 1999; Stanely et al., 1999). High flavonoids content of E. hyssopifolium (Ghosal and Jaiswal, 1980) impart a good anti oxidant property which might be in turn responsible for its $A R$ inhibiting potential. These plants could be further evaluated for bio guided fractionation to emerge out with a new AR inhibitor molecule.

\section{ACKNOWLEDGEMENTS}

One of the authors, Mr. Mayurkumar Patel, would like to thank All India Council for Technical Education (AICTE), New Delhi, for providing the financial assistance, in the form of National Doctoral Fellowship (NDF) to carry out this work.

\section{REFERENCES}

Ananthi A, Prakasam A, Pugalendi KV. (2003) Antihyperglycemic activity of Eclipta alba leaf on alloxan-induced diabetic rats. Yale J. Biol. Med. 76, 97-102.

Baskaran K, Kizar Ahmat B, Shanmugasundaram KR, Shanmugasundaram ER. (1990) Antidiabetic effect of a leaf extract from Gymnema sylvestre in non-insulindependent diabetes mellitus patients. J. Ethnopharmacol.
30, 295-300.

Brownlee M. (2001) Biochemistry and molecular biology of diabetic. Complications. Nature 414, 813820.

Carper DA, Wistow G, Nishimura C. (1989) A superfamily of NADPH-dependent reductases in eukaryotes and prokaryotes. Exp. Eye Res. 49, 377388.

Collier M, Small M. (1991) The role of the polyol pathway in diabetes mellitus. Brit. J. Hosp. Med. 45, 38-40.

Crabbe MJC, Goode D. (1998) Aldose reductase: a window to the treatment of diabetic complications? Prog. Retin. Eye Res. 17, 313-383.

Fuente JA, Manzanaro S. (2003) Aldose reductase inhibitors from natural sources. Nat. Prod. Rep. 20, 243-251.

Fujita T, Ohira K, Miyatake K, Nakana Y, Nakayama M. (1995) Inhibitory effects of perillosides A and C, and related monoterpene glycosides on aldose reductase and their structure activity relationships. Chem. Pharm. Bull. 43, 920-926.

Ghosal S, Jaiswal DK. (1980) Chemical constituents of gentianaceae XXVIII: Flavonoids of Enicostemma hyssopifolium (willd.) verd. J. Pharm. Sci-US. 69, 53-56.

Guzman A, Guerrero RO. (2005) Inhibition of aldose reductase by herbs extracts and natural substances and their role in prevention of cataracts. Rev. Cubana. Planta Med. 10, 3-4.

Halder N, Joshi S, Gupta SK. (2003) Lens aldose reductase inhibiting potential of some indigenous plants. J. Ethnopharmacol. 86, 113-116.

Haraguchi H, Ohmi I, Sakai S, Fukuda A, Toihara Y, Fujimoto T, Okamura N, Yagi A. (1996) Effect of Polygonum hydropiper sulfated flavonoids on lens aldose reductase and related enzymes. J. Nat. Prod. 59, 443-445.

Haraguchi, Kanada M, Fukuda A, Naruse K, Okamura N, Yagi A. (1998) An inhibitor of aldose reductase and sorbitol accumulation from Anthocepharus chinensis. Planta Med. 64, 68-69.

Hayman, S, Kinoshita JH. (1965) Isolation and properties of lens aldose reductase. J. Biol. Chem. 240, 877-882.

Heyningen RV. (1959) Formation of polyols by the lens of the rat with sugar cataract. Nature 184, 194195. 
Jung SH, Lee YS, Lim SS, Kim YS, Shin KH. (2002) Isoflavonoids from the rhizomes of Belamcanda chinensis and their effects on aldose reductase and sorbitol accumulation in streotozotocin induced diabetic rat tissues. Arch. Pharm. Res. 25, 306-312.

Kador PF. (1988) The role of aldose reductase in the development of diabetic complications. Med. Res. Rev. 8, 325-352.

Kim YS, Kim NH, Jung DH, Jang DS, Lee YM, Kim JM, Kim JS. (2008) Genistein inhibits aldose reductase activity and high glucose-induced TGF- $\beta 2$ expression in human lens epithelial cells. Eur. J. Pharmacol. 594, 18-25.

Kohda H, Tanaka S, Yamakoa Y, Yahara S, Nohara T, Tanimoto T, Tanaka A. (1989) Studies on lens-aldose reductase inhibitor in medicinal Plants. II. Active constituents of Monochasma savatierii Franch. Et Maxim. Chem. Pharm. Bull. 37, 3153-3154.

Lee S, Shim SH, Kim JS, Shin KH, Kang SS. (2005) Aldose Reductase Inhibitors from the Fruiting Bodies of Ganoderma Applanatum. Biol. Pharm. Bull. 28, 1103-1105.

Lim SS, Jung SH, Ji J, Shin KH, Keum SR. (2001) Synthesis of flavonoids and their effects on aldose reductase and sorbitol accumulation in streptozotocin induced diabetic rat tissues. J. Pharm. Pharmacol. 53, 653-668.

Lowry OH, Rosebrough NH, Farr AL, Randall RJ. (1951) Protein measurement with the folin phenol reagent. J. Biol. Chem. 193, 265-275.

Matsuda H, Nishida N, Yoshikawa M. (2002) Antidiabetic principles of natural medicines. V. Aldose reductase inhibitors from Myrcia multiflora DC. (2): Structures of myrciacitrins III, IV, and V. Chem. Pharm. Bull. 50, 429-431.

Prince PS, Menon VP. (1999) Antioxidant activity of Tinospora cordifolia roots in experimental diabetes. J. Ethnopharmacol. 65, 277-281.

Rosler K, Goodwin RS, Mabry T, Varma SD, Norri J. (1984) Flavonoids with anti-cataract activity from Brickellia arguta. J. Nat. Prod. 47, 316-319.

Shanmugasundaram ER, Rajeswari G, Baskaran K, Rajesh Kumar BR, Shanmugasundaram KR, Kizar Ahmat B. (1990) Use of Gymnema sylvestre leaf extract in the control of blood glucose in insulindependent diabetes mellitus. J. Ethnopharmacol. 30,
281-294.

Srinivasan M, Padmanabhan M, Prince PS. (2005) Effect of aqueous Enicostemma littorale Blume extract on key carbohydrate metabolic enzymes, lipid peroxides and antioxidants in alloxan-induced diabetic rats. J. Pharm. Pharmacol. 57, 497-503.

Stanely M, Prince P, Menon VP, Gunasekaran G. (1999) Hypolipidaemic action of Tinospora cordifolia roots in alloxan diabetic rats. J. Ethnopharmacol. 64, 53-57.

Stanely P, Prince M, Menon VP. (2000) Hypoglycaemic and other related actions of Tinospora cordifolia roots in alloxaninduced diabetic rats. J. Ethnopharmacol. 70, 9-15.

Suryanarayana P, Kumar PA, Saraswat M, Petrash JM, Reddy GB. (2004) Inhibition of aldose reductase by tannoid principles of Emblica officinalis: implications for the prevention of sugar cataract. Mol. Vis. 10, 148-154.

Tomlinson DR, Stevens EJ, Diemel L. (1994) Aldose reductase inhibitors and their potential for the treatment of diabetic complications. Trends Pharm. Sci. 15, 293-297.

Ueda H, Kuroiwa E, Tachibana Y, Kawanishi K, Ayala F. Moriyasu M. (2004) Aldose reductase inhibitors from the leaves of Myrciaria dubia (HB \&K) McVaaugh. Phytomedicine 11, 652-656.

Vasu VT, Aalinkeel R,Gupta S. (2002) Glucose lowering effect of aqueous extract of Enicostemma littorale Blume in diabetes: a possible mechanism of action. J. Ethnopharmacol. 81, 317-320.

Vijayvargia R, Kumar M, Gupta S. (2000) Hypoglycemic effect of aqueous extract of Enicostemma littorale Blume (chhota chirayata) on alloxan induced diabetes mellitus in rats. Indian J. Exp. Biol. 38, 781-784.

Wadood N, Wadood A, Shah SA. (1992) Effect of Tinospora cordifolia on blood glucose and total lipid levels of normal and alloxan-diabetic rabbits. Planta Med. 58, 131-136.

West CD, Rapoport S. (1949) Colorimetric method for the estimation of dulcitol. Proc. Soc. Exp. Biol. 70, 142-145.

Yabe-Nishimura C. (1998) Aldose reductase in glucose toxicity: a potential target for the prevention of diabetic complications. Pharmacol. Rev. 50, 21-33. 